\title{
Corrigendum
}

\section{Network dynamics of HIV risk and prevention in a population-based cohort of young Black men who have sex with men - CORRIGENDUM}

J. Schneider, B. Cornwell, A. Jonas, N. Lancki, R. Behler, B. Skaathun, L. E. Young, E. Morgan, S. Michaels, R. Duvoisin, A. S. Khanna, S. Friedman, P. Schumm, E. Laumann, for the uConnect Study Team

doi: 10.1017/nws.2016.27, Published by Cambridge University Press, 01 February 2017.

The order of the authors in the published article is incorrect. The authors should appear as follows:

J. Schneider, B. Cornwell, A. Jonas, R. Behler, N. Lancki, B. Skaathun, L. E. Young, E. Morgan, S. Michaels, R. Duvoisin, A. S. Khanna, S. Friedman, P. Schumm, E. Laumann, for the uConnect Study Team

The authors regret the error.

\section{Reference}

Schneider J., Cornwell, B., Jonas, A., Lancki, N., Behler, R., Skaathun, B., ... Laumann, E. (2017). Network dynamics of HIV risk and prevention in a population-based cohort of young Black men who have sex with men. Network Science, 1-29. doi: 10.1017/nws.2016.27. 